\title{
Anti-Thyroglobulin IgG in Therapeutic Immunoglobulins: A Reactivity Bias in IgG4 Subclass
}

\author{
Sonia Néron ${ }^{1,2}$, Annie Roy ${ }^{1}$, Nathalie Dussault ${ }^{1}$, Caroline Philipeau ${ }^{1}$ \\ ${ }^{1}$ Héma-Québec, Production Cellulaire, Recherche et Développement, Québec, Canada \\ ${ }^{2}$ Université Laval, Faculté des sciences et de génie, Département de Biochimie et Microbiologie, Québec, \\ Canada \\ Email: sonia.neron@hema-quebec.qc.ca
}

Received 10 June 2014; revised 10 July 2014; accepted 10 August 2014

Copyright (C) 2014 by authors and Scientific Research Publishing Inc.

This work is licensed under the Creative Commons Attribution International License (CC BY). http://creativecommons.org/licenses/by/4.0/

(c) () 0 pen Access

\section{Abstract}

Therapeutic immunoglobulins are used in the treatment of immunodeficiencies as well as several autoimmune and inflammatory diseases. These intravenous immunoglobulins (IVIg) represent the healthy human IgG repertoire, which can be reactive for both self and non-self antigens. A better characterization of IVIg's repertoire is an important aspect to enable its effective utilization as an immunomodulatory treatment. In this study we have investigated the reactivity of IgG IgG $_{2}$, $\mathrm{IgG}_{3}$ and $\mathrm{IgG}_{4}$ present in IVIg for a small selection of antigens, including actin, DNA, ferritin and thyroglobulin. We observed that two commercial preparations of therapeutic immunoglobulins contain very high reactivity for thyroglobulin, which was predominantly detected by IgG $_{4}$. Since $\mathrm{IgG}_{4}$ antibodies can have immunomodulatory properties, these result suggest that these anti-thyroglobulin may have a role in the IVIg treatment of autoimmune disease characterized by high avidity for anti-thyroglobulin antibodies such as Hashimoto's disease.

\section{Keywords}

IgG4, Anti-Thyroglobulin, Human Intravenous Immunoglobulin

\section{Introduction}

Therapeutic immunoglobulins, namely intravenous immunoglobulins (IVIg), are currently used in the treatment of immunodeficiencies as well as several autoimmune and inflammatory diseases (reviewed in [1]). IVIg is constituted of the human healthy IgG repertoire (>98\% IgG), which contains antibodies against pathogens as well as 
natural antibodies [2]. IVIg contain $\operatorname{IgG}_{1}, \operatorname{IgG}_{2}, \mathrm{IgG}_{3}$ and $\operatorname{IgG}_{4}$ in proportions similar to those observed in normal human serum [1]. Overall, anti-inflammatory properties of IVIg are related to their capacities to down-modulate activation of immune cells or to reduce the negative impact of pathologic IgG [1] [3].

However, it is well known that all IgG subclasses are not equal in their potential to modulate immune functions such as complement activation or Fcgamma receptor stimulation [4]. Furthermore, IgG subclasses may also differ in their antigenic targets. For example $\operatorname{IgG}_{1}$ and $\mathrm{IgG}_{3}$ are mostly related to anti-protein response while $\mathrm{IgG}_{2}$ is usually attributed to the anti-carbohydrate response [4] [5]. IgG $_{4}$, the less abundant subclass, have un-

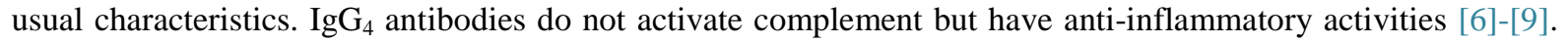
Furthermore, following an in vivo Fab-arm exchange mechanism, the $\mathrm{IgG}_{4}$ molecule can become bispecific, a property that can be associated to anti-inflammatory functions [8] as well as to rheumatoid arthritis [10]. Conversely, several diseases are associated to very high levels of $\mathrm{IgG}_{4}$ in blood and organs leading to the recent de-

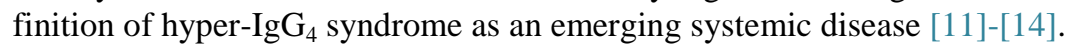

The repertoire of IVIg includes a lot of self-reactive antibodies targeting proteins such as siglec-9 [15], cytokines [16] [17], ferritin and thyroglobulin [18] [19], as well as several surface and intracellular components of human cells [20]-[22]. These autoreactive antibodies are considered to have a role in IVIg mechanisms of action for the treatment of autoimmune and inflammatory disorders [17] [23]-[25]. In this study we have investigated whether IVIg autoreactivity contents could vary according to the four IgG subclasses.

\section{Materials and Methods}

\subsection{Human IgG Preparations}

Two commercial preparations of IVIg were tested, namely GamunexTM from Talecris Biotherapeutics ltd. (Toronto, ON, Canada) and Gammagard from Baxter Corporation, (Mississauga, ON, Canada). Both IVIg preparations were similar in terms of their proportions of IgG1, IgG2, IgG3 and IgG4, which represents $64 \% \pm 3 \%$, $28 \% \pm 4 \%, 4 \% \pm 2 \%$ and $4 \% \pm 1 \%$ of the total IgG content, respectively (data not shown and [26]).

\subsection{IgG reactivity in Direct ELISA}

Reactivity of IgG in IVIg was evaluated by ELISA using a selection of antigens constituted of human transferrin, whole molecules and Fc fragments of murine IgG (Jackson Immuno Research Laboratories, West Grove, PA, USA), bovine actin and histone, salmon dsDNA and human fibronectin (Sigma-Aldrich, Oakville, ON, Canada), human ferritin and thyroglobulin (Calbiochem, San Diego, USA) [25]. Bovine histone and salmon dsDNA were adsorbed at $50 \mu \mathrm{g} / \mathrm{ml}$ in $100 \mathrm{mM}$ citrate buffer $\mathrm{pH} 6.0$ [27]. All other antigens were adsorbed at $10 \mu \mathrm{g} / \mathrm{mL}$ in $100 \mathrm{mM}$ carbonate buffer pH 9.6 [25]. Bound human IgG were revealed with peroxidase-conjugated goat anti-human IgG gamma-chain specific antibodies (Jackson ImmunoResearch) or peroxidase-conjugated mouse antibodies specific to human IgG1, IgG2, IgG3 and IgG4 subclasses (Southern Biotech, Birmingham, Alabama, USA). A solution of $10 \mathrm{mM}$ Phosphate buffered saline $\mathrm{pH} 7.0$ containing $5 \%$ fetal bovine serum (Invitrogen, Burlington, ON, Canada) was used as blocking buffer and as a diluent for IVIg as well as all peroxidase-conjugated antibodies. Non-specific human IgG bindings were determined by using wells coated with $100 \mathrm{mM}$ carbonate buffer alone or containing $0.001 \%$ FBS. When indicated, the strength of IVIg reactivity was determined using two-fold serial dilutions ranging from $250 \mu \mathrm{g} / \mathrm{ml}$ to $8 \mu \mathrm{g} / \mathrm{mL}$ and revealed according to each IgG subclasses as described above. All ELISA analyses were done in triplicate.

\section{Results}

\subsection{IgG Self-Reactivity Is Detected in Both IVIg Preparations}

In a first step, the reactivity pattern was determined for IVIg using a final concentration of $25 \mu \mathrm{g} / \mathrm{mL}$ of total IgG by a direct detection in ELISA (Figure 1). Background for IVIg binding was $0.2 \pm 0.1$ (O.D.) as determined by controls done with diluent (FBS) and uncoated wells (CTL-neg). Both IVIg preparations were tested simultaneously and showed similar capacity to bind dsDNA, actin, ferritin, thyroglobulin and transferrin. In this ELISA system, the total IgG anti-species cross-reactivity of IVIg for murine IgG molecules was comparable to that of transferrin, thyroglobulin and ferritin antigens Analysis done with both IVIg adjusted to $250 \mu \mathrm{g} / \mathrm{mL}$ resulted in O.D. varying from 1.0 to more than 3.5 in most cases (data not shown) indicating that these reactivity 


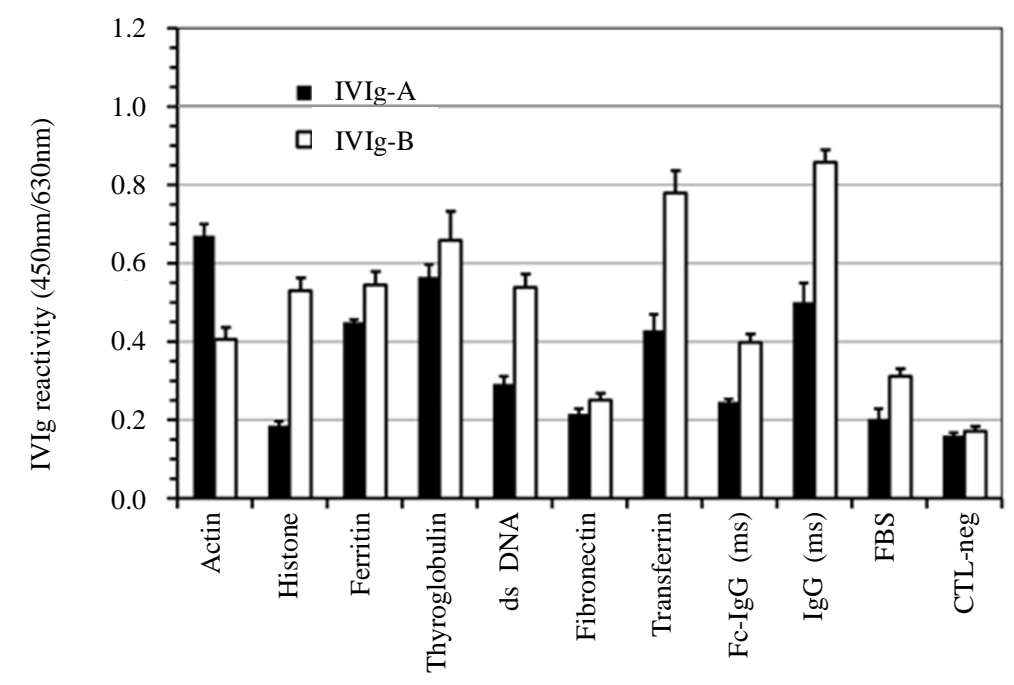

Figure 1. IVIg self-reactivity is present in both preparations. Total IgG in IVIg preparations were tested at a final concentration of $25 \mu \mathrm{g} / \mathrm{ml}$ and their reactivity was screened on a small selection of antigens as indicated. IVIg preparations A and B stand for Gamunex and Gammagard, respectively. Data are expressed as the mean of triplicate $\pm \mathrm{SD}$.

patterns were proportional to the amount of human IgG in tested samples.

\subsection{Self-Reactivity Is Present in IgG1, IgG3 and IgG4}

To compensate for the lower concentration of IgG3 and IgG4, IVIg-A and IVIg-B were adjusted to $250 \mu \mathrm{g} / \mathrm{mL}$ and their reactivity patterns were determined for each IgG subclasses (Figure 2). Background reactivity for IgG1, IgG3 and IgG4 was higher for IVIg-A when compared to IVIg-B, resulting in a similar level of specific binding for most selected antigens. As expected, IgG2 was reactive only for mouse Fc-IgG, which is known to have several glycosylation sites. IgG1, IgG3 and IgG4 showed comparable pattern of reactivity and even though IgG1 is about 10-fold more abundant than IgG3 and IgG4, their level of reactivity was also similar. In fact, IgG3 and IgG4 were characterized by a higher level of reactivity for bovine actin, salmon dsDNA, as well as human ferritin and thyroglobulin.

\subsection{IgG4 Contains Most Anti-Thyroglobulin Reactivity}

Based on the above observations, titration of IVIg reactivity was done to evaluate the strength of IgG1, IgG2, IgG3 and IgG4 binding on human ferritin and thyroglobulin, which are targets naturally present in human blood [18]. Serial dilution concentrations were established in function of the total IgG content while reactivity was detected using antibody specific for each IgG subclass. Bovine actin reactivity as well as background was also assessed in parallel using the same serial dilutions of IgG in both IVIg preparations. These results are representative of four independent experimentations using IVIg-A and three using IVIg-B. The relative reactivities of IgG subclasses for actin, ferritin and thyroglobulin were similar to those observed above for both IVIg (Figure 3) and were all directly proportional to their final concentration. IVIg-A was showing high IgG1 background reactivity as above. Overall, the titration for thyroglobulin reactivity corroborated that the high level of anti-thyroglobulin antibodies, present in both IVIg, is mainly confined to the IgG4 subclass.

\section{Discussion}

In this study we showed that IVIg content of autoreactive antibodies varied according to their isotypes. Furthermore, we highlighted that anti-thyroglobulin was mainly constituted of IgG4. These observations lead us to question whether that reactivity for human thyroglobulin in two IVIg preparations may have some importance in its utilization for the treatment of the autoimmune disorder Hashimoto disease. Hashimoto disease is an IgG4- 

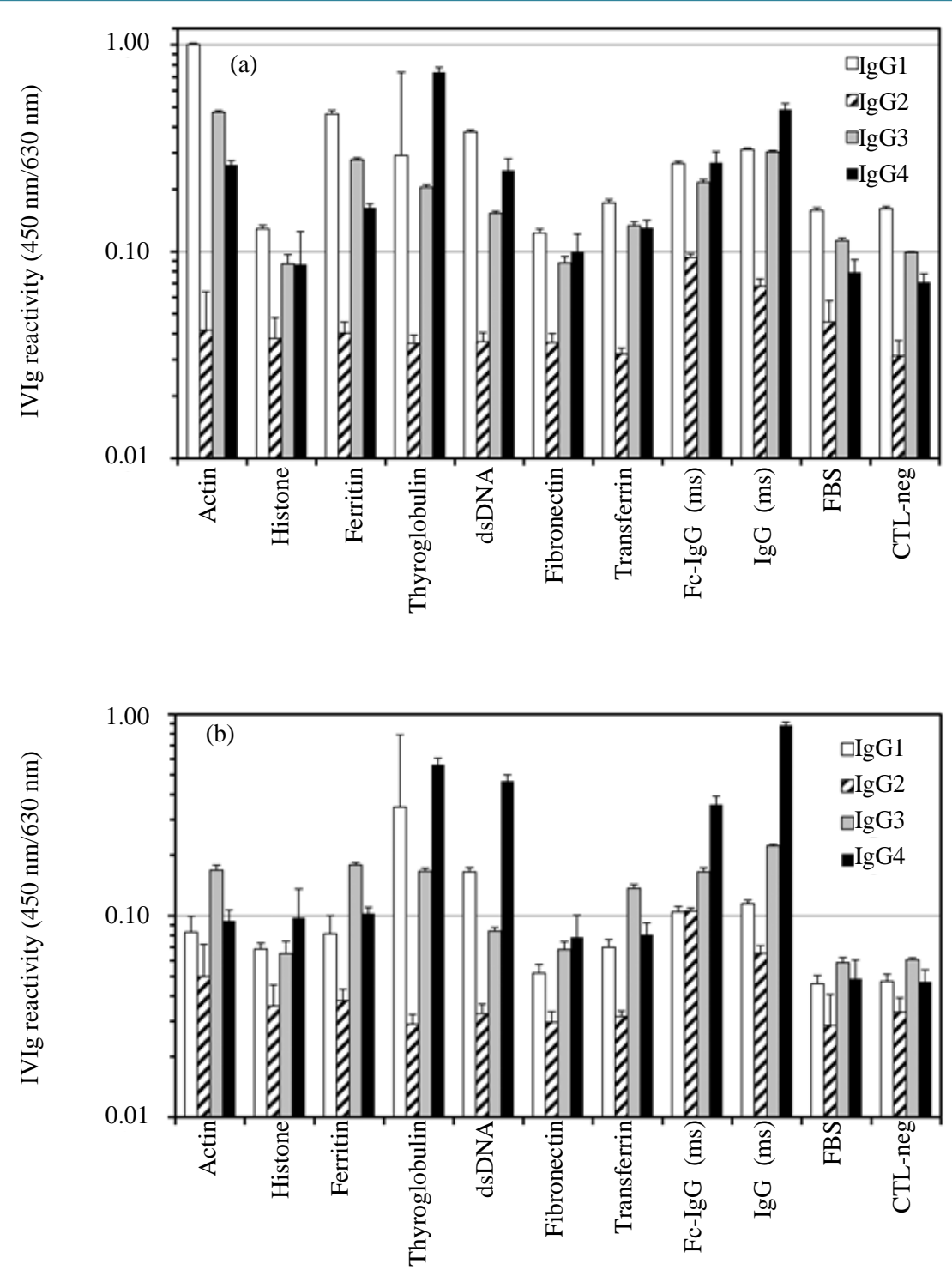

Figure 2. IgG3 and IgG4 have high levels of self-reactivity. IVIg preparations (a) (Gamunex) and (b) (Gammagard) were adjusted at a final concentration of $250 \mu \mathrm{g} / \mathrm{ml}$ according to their total IgG content. The binding of IgG1 IgG2 IgG3 and IgG4 was revealed using antibody specific for each subclasses as described in Material and methods. Data are expressed as the mean of triplicate \pm SD.

related systemic disease characterized by autoantibodies directed against thyroglobulin or thyroid peroxidase [28]. Besides, these autoreactive antibodies can be associated to IgG4 antibodies showing high reactivity for their targets [29]-[31]. Furthermore, high avidity of thyroglobulin antibody in sera from patients with Hashimoto's thyroiditis often corresponds to high disease activity [32].

Previous studies done by Kazatchkine and collaborators underline a link between IVIg and anti-thyroglobulin related to reestablishment of idiotypic networks [33]-[36]. Our observations showing the presence of anti-thyroglobulin IgG4 inside IVIg preparation suggests that IVIg-IgG4 anti-thyroglobulin having lower avidity may succeed to alter their high avidity counterparts. IgG4 are able to self-associate to other IgG molecules [37]-[39] and have anti-inflammatory characteristics conferred by their extraordinary capacity to perform dynamic Fab arm exchange [6] [7] [38]. Therefore, the presence of anti-thyroglobulin typical of IgG4 subclass in IVIg, may help the immune system to dampen inappropriate binding of thyroglobulin in Hashimoto's patient.

The autoreactivity content of IVIg has already been proposed as a possible target for the preparation of 

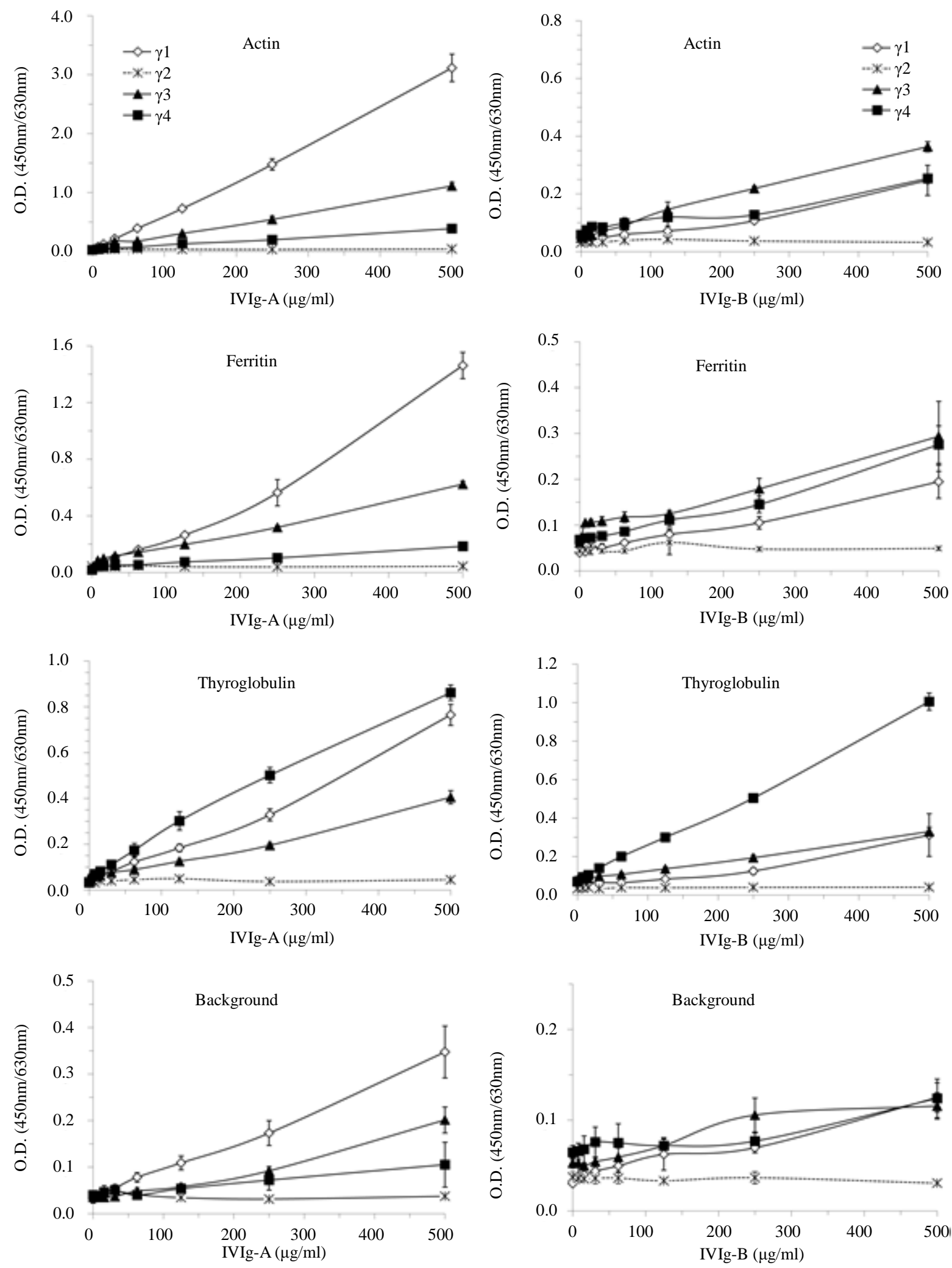

Figure 3. IgG4 is highly reactive for thyroglobulin. IgG subclasses reactivity in IVIg (panel A—Gamunex; panel BGammagard) were titrated to determine the level of reactivity specific for actin, ferritin, thyroglobulin as well as FBS for background reactivity. 
substitute [18] [40]. In this study we bring new insights indicating that fractionation of IgG4 prepared from human plasma could also be investigated as a substitute to treat IgG4-related disorders.

\section{Acknowledgements}

We are grateful to Marc Cloutier PhD for excellent critical review and manuscript editing.

\section{References}

[1] Schwab, I. and Nimmerjahn, F. (2013) Intravenous Immunoglobulin Therapy: How Does IgG Modulate the Immune System? Nature Review Immunology, 13, 176-189. http://dx.doi.org/10.1038/nri3401

[2] Gelfand, E.W. (2012) Intravenous Immune Globulin in Autoimmune and Inflammatory Diseases. New England Journal of Medicine, 367, 2015-2025. http://dx.doi.org/10.1056/NEJMra1009433

[3] Aschermann, S., Lux, A., Baerenwaldt, A., Biburger, M. and Nimmerjahn, F. (2010) The Other Side of Immunoglobulin G: Suppressor of Inflammation. Clinical and Experimental Immunology, 160, 161-167.

http://dx.doi.org/10.1111/j.1365-2249.2009.04081.x

[4] Salfeld, J.G. (2007) Isotype Selection in Antibody Engineering. Nature Biotechnology, 25, 1369-1372. http://dx.doi.org/10.1038/nbt1207-1369

[5] von Gunten, S., Smith, D.F., Cummings, R.D., Riedel, S., Miescher, S., Schaub, A., Hamilton, R.G. and Bochner, B.S. (2009) Intravenous Immunoglobulin Contains a Broad Repertoire of Anticarbohydrate Antibodies That Is Not Restricted to the IgG(2) Subclass. Journal of Allergy and Clinical Immunology, 123, 1268-1276. http://dx.doi.org/10.1016/j.jaci.2009.03.013

[6] van der Neut Kolfschoten, M., Schuurman, J., Losen, M., et al. (2007) Anti-Inflammatory Activity of Human IgG4 Antibodies by Dynamic Fab Arm Exchange. Science, 317, 1554-1557. http://dx.doi.org/10.1126/science.1144603

[7] Burton, D.R. and Wilson, I.A. (2007) Immunology. Square-Dancing Antibodies. Science, 317, 1507-1508. http://dx.doi.org/10.1126/science.1148905

[8] Rispens, T., Ooijevaar-de Heer, P., Bende, O. and Aalberse, R.C. (2011) Mechanism of Immunoglobulin G4 Fab-Arm Exchange. Journal of the American Chemical Society, 133, 10302-10311. http://dx.doi.org/10.1021/ja203638y

[9] Nirula, A., Glaser, S.M., Kalled, S.L. and Taylor, F.R. (2011) What Is IgG4? A Review of the Biology of a Unique Immunoglobulin Subtype. Current Opinion in Rheumatology, 23, 119-124. http://dx.doi.org/10.1097/BOR.0b013e3283412fd4

[10] Wang, W. and Li, J. (2011) Identification of Natural Bispecific Antibodies against Cyclic Citrullinated Peptide and Immunoglobulin G in Rheumatoid Arthritis. PLoS One, 6, e16527. http://dx.doi.org/10.1371/journal.pone.0016527

[11] Ebbo, M., Daniel, L., Pavic, M., et al. (2012) IgG4-Related Systemic Disease: Features and Treatment Response in a French Cohort: Results of a Multicenter Registry. Medicine, 91, 49-56. http://dx.doi.org/10.1097/MD.0b013e3182433d77

[12] Ebbo, M., Grados, A., Daniel, L., Vely, F., Harle, J.R., Pavic, M. and Schleinitz, N. (2012) IgG4-Related Systemic Disease: Emergence of a New Systemic Disease? Literature Review. La Revue de Médecine Interne, 33, 23-34. http://dx.doi.org/10.1016/j.revmed.2011.08.012

[13] Zen, Y. and Nakanuma, Y. (2010) IgG4-Related Disease: A Cross-Sectional Study of 114 Cases. American Journal of Surgical Pathology, 34, 1812-1819. http://dx.doi.org/10.1097/PAS.0b013e3181f7266b

[14] Maehara, T., Moriyama, M., Nakashima, H., Miyake, K., Hayashida, J.N., Tanaka, A., Shinozaki, S., Kubo, Y. and Nakamura, S. (2012) Interleukin-21 Contributes to Germinal Centre Formation and Immunoglobulin G4 Production in IgG4-Related Dacryoadenitis and Sialoadenitis, So-Called Mikulicz'S Disease. Annals of the Rheumatic Diseases, 71, 2011-2020. http://dx.doi.org/10.1136/annrheumdis-2012-201477

[15] von Gunten, S., Schaub, A., Vogel, M., Stadler, B.M., Miescher, S. and Simon, H.U. (2006) Immunologic and Functional Evidence for Anti-Siglec-9 Autoantibodies in Intravenous Immunoglobulin Preparations. Blood, 108, 4255-4259. http://dx.doi.org/10.1182/blood-2006-05-021568

[16] Gelfand, E.W. (2001) Antibody-Directed Therapy: Past, Present, and Future. Journal of Allergy and Clinical Immunology, 108, S111-S116. http://dx.doi.org/10.1067/mai.2001.117824

[17] Sewell, W.A.C. and Jolles, S. (2002) Immunomodulatory Action of Intravenous Immunoglobulin. Immunology, 107, 387-393. http://dx.doi.org/10.1046/j.1365-2567.2002.01545.x

[18] Lamoureux, J., Aubin, E. and Lemieux, R. (2004) Autoantibodies Purified from Therapeutic Preparations of Intravenous Immunoglobulins (IVIg) Induce the Formation of Autoimmune Complexes in Normal Human Serum: A Role in the in Vivo Mechanisms of Action of IVIg? International Immunology, 16, 929-936. 
http://dx.doi.org/10.1093/intimm/dxh094

[19] Dimitrov, J.D., Planchais, C., Kang, J., Pashov, A., Vassilev, T.L., Kaveri, S.V. and Lacroix-Desmazes, S. (2010) Heterogeneous Antigen Recognition Behavior of Induced Polyspecific Antibodies. Biochemical and Biophysical Research Communications, 398, 266-271. http://dx.doi.org/10.1016/j.bbrc.2010.06.073

[20] Bussone, G., Dib, H., Dimitrov, J.D., Camoin, L., Broussard, C., Tamas, N., Guillevin, L., Kaveri, S.V. and Mouthon, L. (2009) Identification of Target Antigens of Self-Reactive IgG in Intravenous Immunoglobulin Preparations. Proteomics, 9, 2253-2262. http://dx.doi.org/10.1002/pmic.200800819

[21] Schaub, A., Wymann, S., Heller, M., Ghielmetti, M., Beleznay, Z., Stadler, B.M., Bolli, R. and Miescher, S. (2007) Self-Reactivity in the Dimeric Intravenous Immunoglobulin Fraction. Annals of the New York Academy of Sciences, 1110, 681-693. http://dx.doi.org/10.1196/annals.1423.071

[22] Néron, S. and Roy, A. (2012) Overview of IgG-Reactivity in Therapeutic Immunoglobulins Revealed by Protein Array Analysis. Biochemistry \& Analytical Biochemistry, S8, 001.

[23] Ballow, M. (2011) The IgG Molecule as a Biological Immune Response Modifier: Mechanisms of Action of Intravenous Immune Serum Globulin in Autoimmune and Inflammatory Disorders. Journal of Allergy and Clinical Immunology, 127, 315-323. http://dx.doi.org/10.1016/j.jaci.2010.10.030

[24] Tha-In, T., Bayry, J., Metselaar, H.J., Kaveri, S.V. and Kwekkeboom, J. (2008) Modulation of the Cellular Immune System by Intravenous Immunoglobulin. Trends in Immunology, 29, 608-615. http://dx.doi.org/10.1016/j.it.2008.08.004

[25] de Grandmont, M.J., Racine, C., Roy, A., Lemieux, R. and Néron, S. (2003) Intravenous Immunoglobulins Induce the in Vitro Differentiation of Human B Lymphocytes and the Secretion of IgG. Blood, 101, 3065-3073. http://dx.doi.org/10.1182/blood-2002-06-1684

[26] Siegel, J. (2005) Immune Globulins: Therapeutic, Pharmaceutical, Cost, and Administration Considerations. Pharmacy Practice News, Special Edition, 15-19.

[27] Kaushik, A., Lim, A., Poncet, P., Ge, X.R. and Dighiero, G. (1988) Comparative Analysis of Natural Antibody Specificities among Hybridomas Originating from Spleen and Peritoneal Cavity of Adult NZB and BALB/c Mice. Scandinavian Journal of Immunology, 27, 461-471. http://dx.doi.org/10.1111/j.1365-3083.1988.tb02372.X

[28] Li, Y., Nishihara, E. and Kakudo, K. (2011) Hashimoto’s Thyroiditis: Old Concepts and New Insights. Current Opinion in Rheumatology, 23, 102-107. http://dx.doi.org/10.1097/BOR.0b013e328341378c

[29] Adler, T.R., Beall, G.N., Curd, J.G., Heiner, D.C. and Sabharwal, U.K. (1984) Studies of Complement Activation and IgG Subclass Restriction of Anti-Thyroglobulin. Clinical and Experimental Immunology, 56, 383-389.

[30] Liu, W., Meckel, T., Tolar, P., Sohn, H.W. and Pierce, S.K. (2010) Intrinsic Properties of Immunoglobulin IgG1 Isotype-Switched B Cell Receptors Promote Microclustering and the Initiation of Signaling. Immunity, 32, 778-789. http://dx.doi.org/10.1016/j.immuni.2010.06.006

[31] Xie, L.-D., Gao, Y., Li, M.-R., Lu, G.Z. and Guo, X.-H. (2008) Distribution of Immunoglobulin G Subclasses of AntiThyroid Peroxidase Antibody in Sera from Patients with Hashimoto's Thyroiditis with Different Thyroid Functional Status. Clinical \& Experimental Immunology, 154, 172-176. http://dx.doi.org/10.1111/j.1365-2249.2008.03756.X

[32] Zhang, Y., Gao, Y., Li, M., Xie, L., Huang, Y. and Guo, X. (2010) Avidity of Thyroglobulin Antibody in Sera from Patients with Hashimoto's Thyroiditis with Different Thyroid Functional Status. Clinical and Experimental Immunology, 161, 65-70.

[33] Dietrich, G. and Kazatchkine, M.D. (1990) Normal Immunoglobulin G (IgG) for Therapeutic Use (Intravenous Ig) Contain Antiidiotypic Specificities against an Immunodominant, Disease-Associated, Cross-Reactive Idiotype of Human Anti-Thyroglobulin Autoantibodies. The Journal of Clinical Investigations, 85, 620-625. http://dx.doi.org/10.1172/JCI114483

[34] Dietrich, G., Piechaczyk, M., Pau, B. and Kazatchkine, M.D. (1991) Evidence for a Restricted Idiotypic and Epitopic Specificity of Anti-Thyroglobulin Autoantibodies in Patients with Autoimmune Thyroiditis. European Journal of Immunology, 21, 811-814. http://dx.doi.org/10.1002/eji.1830210340

[35] Dietrich, G., Varela, F.J., Hurez, V., Bouanani, M. and Kazatchkine, M.D. (1993) Selection of the Expressed B Cell Repertoire by Infusion of Normal Immunoglobulin G in a Patient with Autoimmune Thyroiditis. European Journal of Immunology, 23, 2945-2950.

[36] Rossi, F. and Kazatchkine, M.D. (1989) Antiidiotypes against Autoantibodies in Pooled Normal Human Polyspecific Ig. The Journal of Immunology, 143, 4104-4109.

[37] Nezlin, R. (2010) Interactions between Immunoglobulin G Molecules. Immunology Letters, 132, 1-5. http://dx.doi.org/10.1016/j.imlet.2010.06.006

[38] Aalberse, R.C., Stapel, S.O., Schuurman, J. and Rispens, T. (2009) Immunoglobulin G4: An Odd Antibody. Clinical 
and Experimental Allergy, 39, 469-477. http://dx.doi.org/10.1111/j.1365-2222.2009.03207.x

[39] Rispens, T., Ooievaar-De Heer, P., Vermeulen, E., Schuurman, J., van der Neut Kolfschoten, M. and Aalberse, R.C. (2009) Human IgG4 Binds to IgG4 and Conformationally Altered IgG1 via Fc-Fc Interactions. The Journal of Immunology, 182, 4275-4281. http://dx.doi.org/10.4049/jimmunol.0804338

[40] Lamoureux, J., Aubin, E. and Lemieux, R. (2003) Autoimmune Complexes in Human Serum in Presence of Therapeutic Amounts of Intravenous Immunoglobulins. Blood, 101, 1660-1662. http://dx.doi.org/10.1182/blood-2002-08-2598 
Scientific Research Publishing (SCIRP) is one of the largest Open Access journal publishers. It is currently publishing more than 200 open access, online, peer-reviewed journals covering a wide range of academic disciplines. SCIRP serves the worldwide academic communities and contributes to the progress and application of science with its publication.

Other selected journals from SCIRP are listed as below. Submit your manuscript to us via either submit@scirp.org or Online Submission Portal.
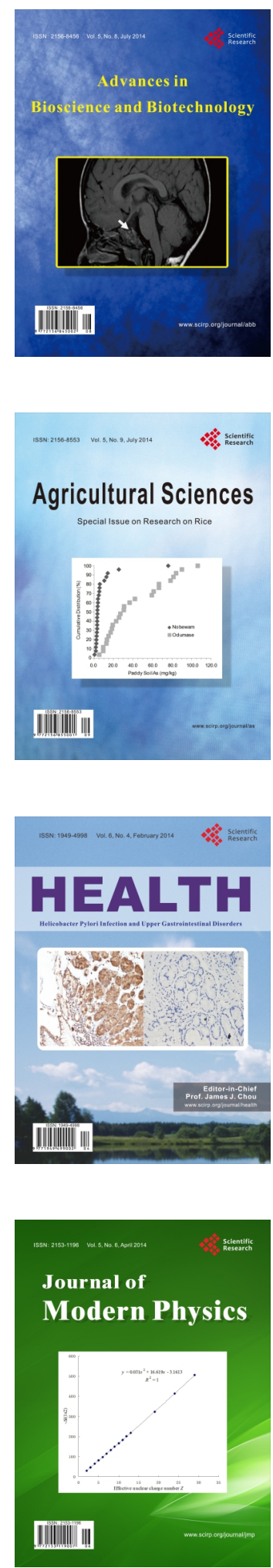
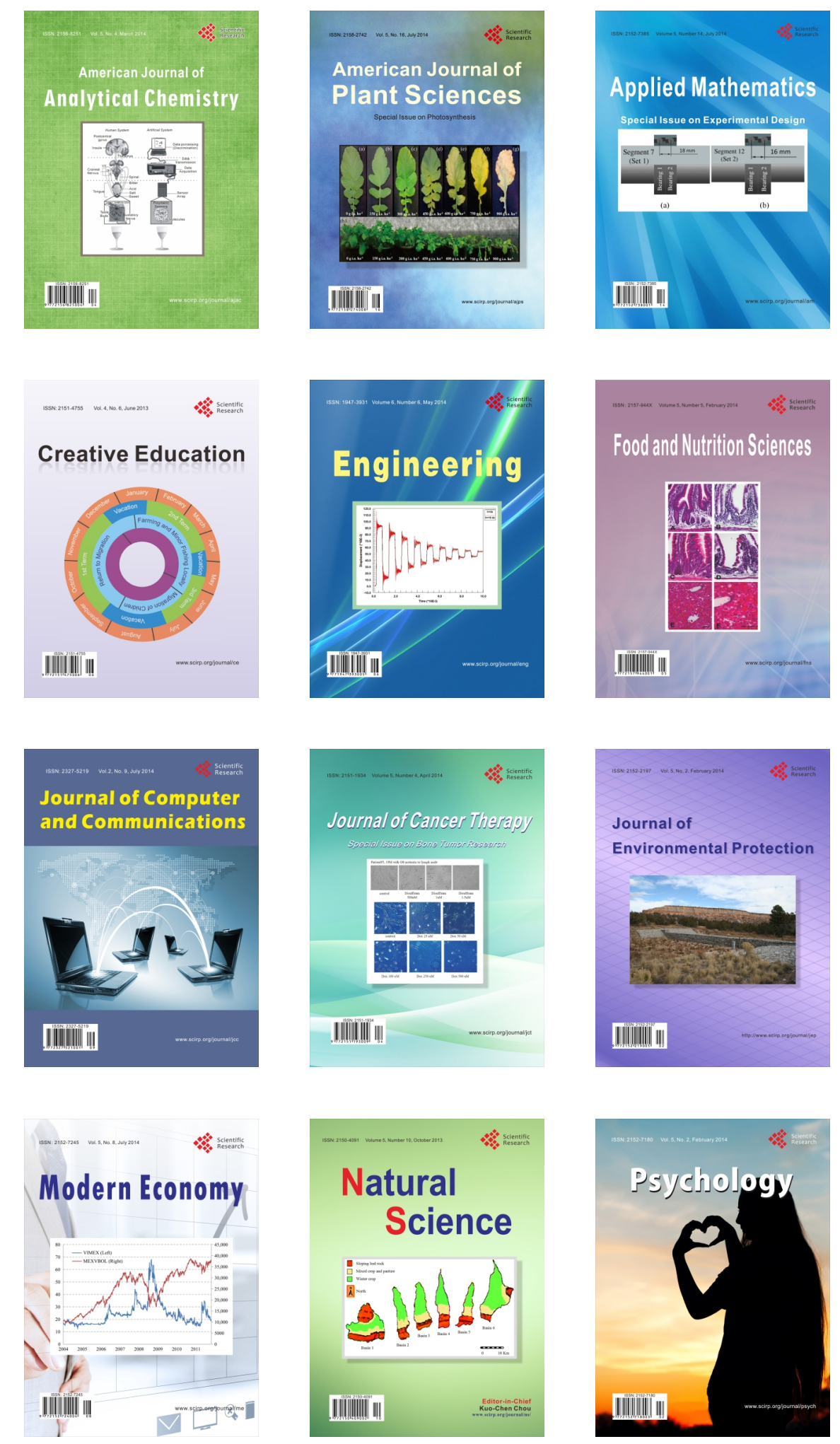